\title{
Influence of the Prosumer Allocation and Heat Production on a District Heating Network
}

\author{
Maria Alessandra Ancona*, Michele Bianchi, Lisa Branchini, Andrea De Pascale, \\ Francesco Melino, Antonio Peretto and Jessica Rosati
}

Department of Industrial Engineering (DIN), Alma Mater Studiorum-Università di Bologna, Bologna, Italy

To face the climate change and global warming issues, European countries have set new targets in order to reduce the $\mathrm{CO}_{2}$ emissions to $40 \%$ by 2030 and to $80 \%$ by 2050 . The district heating networks, and in particular low-temperature networks, due to their efficient heat supply and distribution represent a key point for meeting these goals, as well as the renewable sources integration. Nowadays, in fact, about $40 \%$ of the energy consumed in Europe is for heating, most of which is provided by fossil fuels employment. This article concerns the smart district heating, namely, the possibility of a bidirectional energy exchange between the district heating network and the connected users. The main

Edited by: Konstantinos Kyprianidis, Mälardalen University College,

Sweden

Reviewed by:

Georgios Mavropoulos,

National Technical University of Athens, Greece

Lianshan Lin,

Oak Ridge National Laboratory (DOE), United States

${ }^{*}$ Correspondence: Maria Alessandra Ancona maria.ancona2@unibo.it

Specialty section: This article was submitted to Engine and Automotive Engineering, a section of the journal Frontiers in Mechanical Engineering

Received: 30 October 2020 Accepted: 08 February 2021

Published: 12 April 2021

Citation: Ancona MA, Bianchi M, Branchini L, De Pascale A, Melino F, Peretto $A$ and

Rosati J (2021) Influence of the Prosumer Allocation and Heat Production on a District Heating Network.

Front. Mech. Eng 7:623932. doi: 10.3389/fmech.2021.623932 purpose of this study is to evaluate the possibility of including a prosumer -that is, a customer who can both consume and produce heat - in an existing small/medium district heating network. To this purpose, an in-house-developed software has been applied to analyze whether and which user of the district heating network is more suitable to be set as prosumer and the effect of the installed distributed generation system on the network. The results show how the choice of a prosumer over another and how the amount of exchanged thermal power affect the performance of the network, with a consequent need of a modification in its operation and management.

\section{Keywords: smart district heating, thermohydraulic optimization analysis, distributed generation, thermal prosumer, management optimization}

\section{INTRODUCTION}

According to the recent legislations and policies, European countries have to reach new targets in terms of $\mathrm{CO}_{2}$ emissions. The new goals are set in order to decrease the current emissions level, compared to the one of the 1990 , of $40 \%$ by 2030 and up to $80 \%$ by 2050 (European Climate Change Programme, 2020; Lehmann et al., 2019; Mathiesen et al., 2019). In order to reduce the $\mathrm{CO}_{2}$ of this significant amount, one of the strategies to be implemented consists in the improvement of energy systems efficiency and, at the same time, promoting the increase in the renewable sources exploitation by a major integration of renewable-based systems for energy production. In this context, the heating sector plays an important role; indeed, in the European Union, about $50 \%$ of the final energy demand is due to the heating sector (Kozarcanin et al., 2019). Furthermore, in EU Countries, an amount equal to $27 \%$ of the total final energy consumption is attributable to the household sector, most of which is due to the thermal request (Statistical Office of the European Communities, 1990). In this respect, about two-thirds of the household total energy demand is used for space heating (Statistical Office of the European Communities, 1990). 
Thereby, an important role is played by the district heating $(\mathrm{DH})$, and in particular the low-temperature $\mathrm{DH}$. The use of lowtemperature district heating, under $50^{\circ} \mathrm{C}$, allows reduction of the heat losses along the pipelines and the exploitation of the lowenthalpy thermal energy sources and/or to recover the heat wasted from industries, with the consequent increase in the heat distribution efficiency (Schmidt et al., 2017).

Nowadays, in the European Union, the district heating supplies about $30 \%$ of the heat demand, $12 \%$ of which is for domestic hot water and space heating in residential buildings (Paardekooper et al., 2018).

During the years, the district heating development can be divided into five different generations. The first generation of $\mathrm{DH}$ systems was first introduced in the 1880's in the Unites States. The main characteristic of this generation is the use of pressurized steam as a transportation media operating with high temperature. In fact, because of its large enthalpy content, steam was considered a good carrier fluid. However, the use of high temperatures undermines issues related to the reliability and safety of the network and high heat losses. In the second generation, which has been developed in the 1930's, indeed, the carrier fluid consists in pressurized hot water with a temperature above $100^{\circ} \mathrm{C}$. Even the third generation of $\mathrm{DH}$ was based on the employment of hot water but with temperatures below $100^{\circ} \mathrm{C}$ with a consequent increase in the network efficiency. Nevertheless, the needs for greater security, reliability as flexibility of the energy systems, and the renewable energy source integration entail the use of even lower temperatures (Lund et al., 2014). Therefore, with the fourthgeneration district heating the temperature of water distribution has further decreased around $50-60^{\circ} \mathrm{C}$ (Lund et al., 2010). Consequently, it allows the recovery of the waste heat from the electric power plant by collecting it and sending it to the users when required. At present, the fifth generation of district heating is under development. This generation has been designed with the main purpose of further reducing the carrier fluid temperature to avoid the heat losses along the DHN (Buffa et al., 2019). The temperature is controlled by a heat exchanger in order to range from 15 to $25^{\circ} \mathrm{C}$ (von Rhein et al., 2019).

In addition, the low temperature characterizing the last $\mathrm{DH}$ generation promotes the smart district heating $(\mathrm{SDH})$, namely, the possibility of a bidirectional energy exchange between the district heating network and the connected users. The bidirectionality of the flow is possible thanks to the installation of distributed generation (DG) systems at the final users, allowing the latter to act both as consumers and as producers (the so-called prosumers) (Bünning et al., 2018; Pass et al., 2018; The European Comission, 2015).

In this context, this study addresses the smart district heating topic with the main aim to investigate the possibility of converting the users of a given DHN into prosumers and how this action will affect the network performance. An existing small/ medium size district heating network located within a university campus in the north of Italy has been considered as a case study. To this purpose, an in-house-developed software has been applied in order to analyze whether and which user of the district heating network is more suitable to be set as prosumer considering both the energy and economic points of view.

\section{SMART DISTRICT HEATING NETWORKS AND USER SUBSTATIONS}

The smart district heating networks (SDHNs) extend the DHN concept by including the possibility of realizing a bidirectional thermal energy exchange between the district heating network and the users thanks to the installation of distributed generation systems. This allows the inclusion of one or more prosumers (i.e., producer and consumer) along the district heating network. A distributed generation system placed at the opportune user will be able to produce a part, the total or more of the needs of the user itself and then simultaneously interact with the district heating network. The difference between the user's need and distributed generation system production will be balanced by the network: the excess of production can be introduced into the network or, on the contrary, the lack of production can be covered by the withdrawal from the network. To ensure the bidirectional energy flux, the traditional user substation has to be deeply modified. In fact, in DHNs, the traditional substation is characterized by a heat exchanger that allows the heat transfer between a primary circuit and a secondary circuit which are connected respectively to the DHN and to the user. On the other hand, in case of the distributed generation systems, a tertiary circuit is necessary in order to connect the distributed generation system with both the network and the user.

To this respect, four different configurations of smart (bidirectional) substation have been elaborated by the authors in a previous study (Ancona et al., 2015). The simplified four schemes are represented in Figure 1 (from 1A to 1D):

- Scheme 1 (feed to return-Figure 1A): a mass flow rate is taken from the feed line of the network and reintroduced in the return line after being heated from the decentralized production system.

- Scheme 2 (feed to feed-Figure 1B): the thermal energy exchange from the decentralized production system and the distribution network affects only the feed line.

- Scheme 3 (return to return-Figure 1C): the thermal energy transfer from the user to the network concerns only the return line of the network.

- Scheme 4 (return to feed-Figure 1D): a mass flow rate is extracted from the return line of the network and reintroduced in the feed line after being heated from the decentralized production system.

According to Figure 1, it is important to point up that the key aspect in converting a traditional district heating network into a smart one is the appropriate choice of one of the schemes of the bidirectional substation. The following observation can be done to highlight their main characteristics.

First, it can be noted that Scheme 1 is not appreciated from the network management point of view, since the temperature increase in the return line of the distributed network (and 

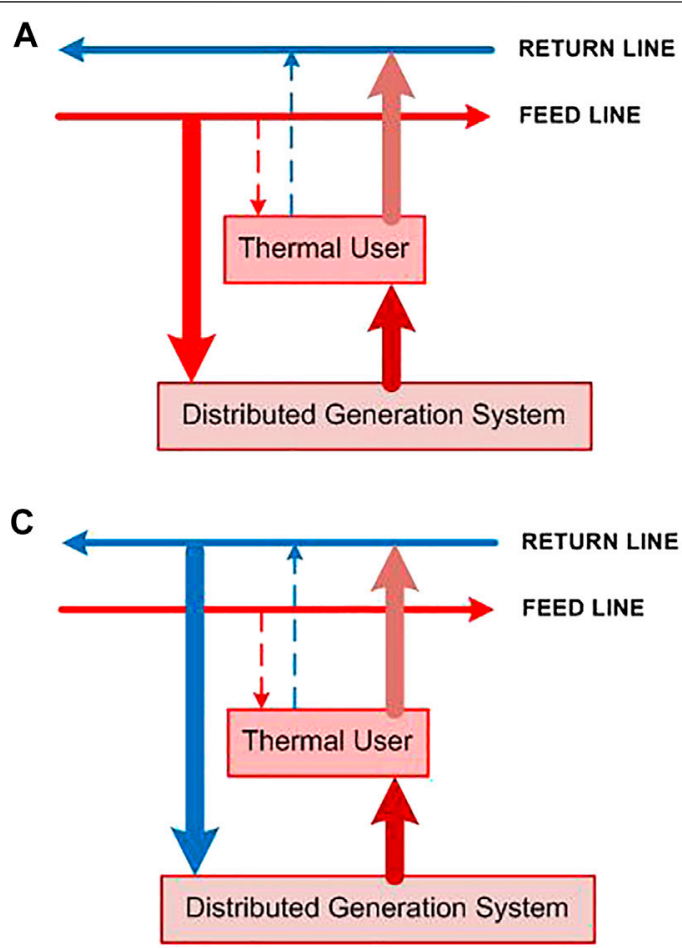
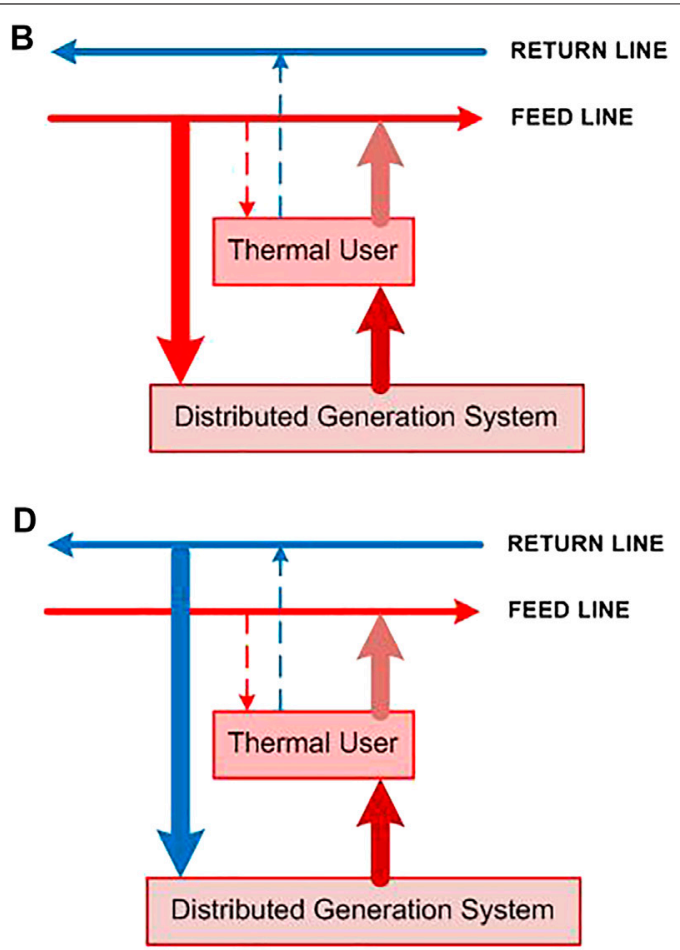

FIGURE 1 | Schematic representation of (A) Scheme 1: feed to return, (B) Scheme 2: feed to feed, (C) Scheme 3: return to return, (D) Scheme 4: return to feed.

thus also in the return temperature to the thermal power station) reduces the efficiency of the centralized production systems of the network. On the other hand, this scheme represents the simplest configuration since it does not affect the network flows and, consequently, the regulation of the network will be easier for the network management.

Furthermore, by considering Scheme 2, it can be observed that the increase in the temperature mainly affects the feed line. Therefore, if the network management is able to predict and optimally control the local production, the feed temperature in correspondence of the thermal power stations can be adapted each time to the new network conditions (i.e., as an example, with the increase in the return temperature at the centralized plant, the feed temperature can be maintained constant or decreased, depending on the chosen strategy). Obviously, if the temperature is kept constant, the users located downstream with respect to the prosumer are fed by a fluid with a higher temperature: this situation may be undesired, since the downstream users may require a constant temperature (e.g., for specific internal processes) or-if equipped them too with a distributed generation system-they may be excluded from further heat introduction into the network. Furthermore, it has to be highlighted that both schemes 1 and 2 need a DG system able to produce heat at the opportune temperature level (i.e., higher than the network feed line level).

On the other hand, as aforementioned for Scheme 1, even for Scheme 3, a temperature increase in the return line occurs, making this configuration not appreciated from the network management viewpoint. Moreover, in this configuration the management of the mass flow rate taken from the return line to the generation systems is more difficult.

Finally, Scheme 4 represents the most complex among the proposed configurations, making the mass flow rate management a key issue. However, the temperature levels of both the feed and the return lines can be kept constant with this configuration, by heating the mass flow rate taken from the return line up to (and not beyond) the feed line temperature level. For this reason, this scheme is the most appreciated by the network management.

\section{CASE STUDY}

With the main purpose of evaluating how the prosumers affect the performance of a district heating network, a small/medium size network has been analyzed. In particular, a portion of an existing DHN consisting of twelve users and located within a university campus in the North of Italy has been considered. To this respect, it has to be underlined that the district heating network provides to the fulfillment of the users' thermal demand for the only space heating. The layout of the analyzed district heating network is shown in Figure 2, highlighting the typology of users and the corresponding ID.

The thermal energy needs of each user in design conditions, assumed for the district heating network evaluation, are presented in Figure 3. As can be observed from the figure, the design thermal power ranges from a minimum value equal to about $25 \mathrm{~kW}$ (in correspondence of the users indicated with ID8) to a 


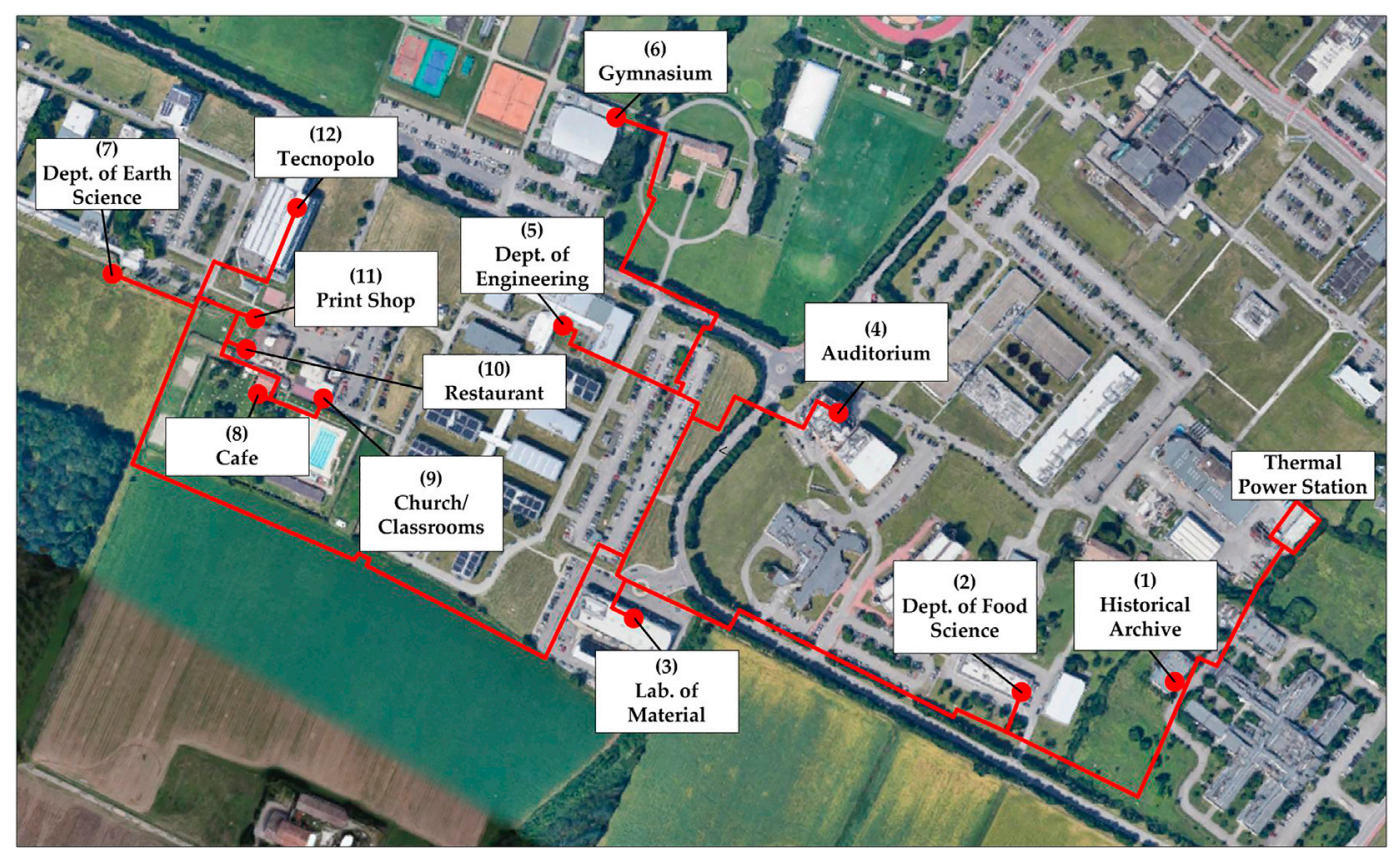

FIGURE 2 | Scheme of the DHN within the university campus.

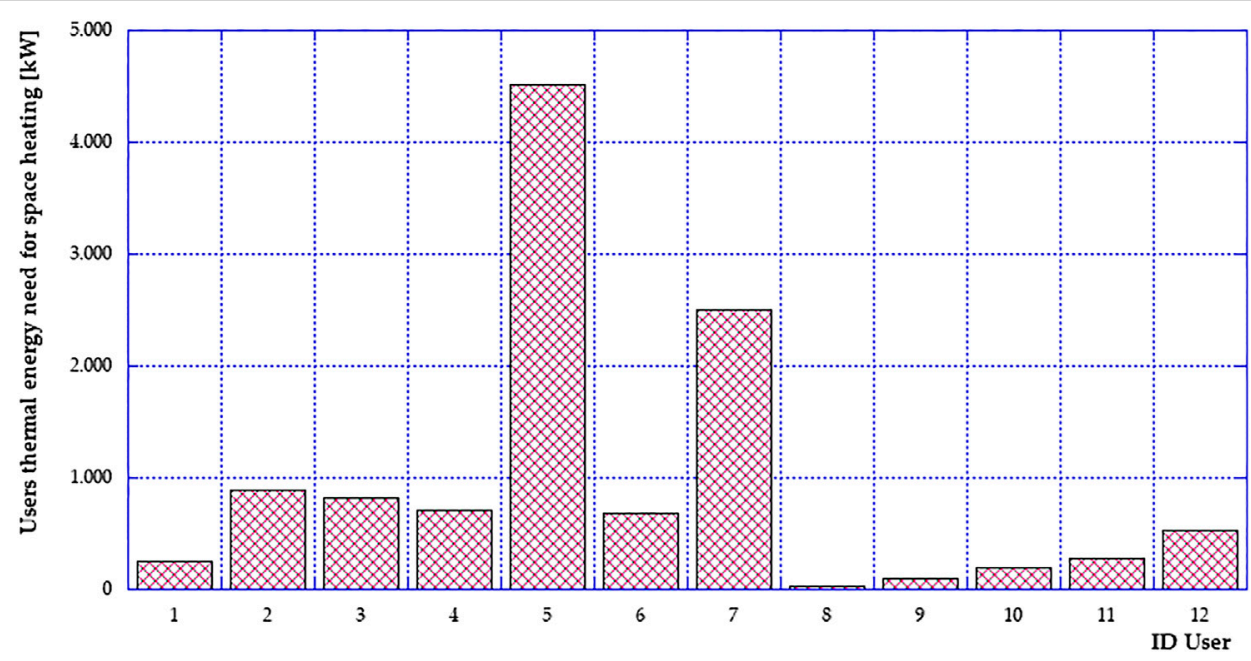

FIGURE 3 | Design of thermal energy needs of the DHN users.

maximum value slightly higher than $4,500 \mathrm{~kW}$ (corresponding to the user identified with ID5).

The thermal power station consists of five boilers and one pumping station. In more detail, the total installed thermal power is equal to $17,500 \mathrm{~kW}$ almost equally divided between the five boilers. Therefore, each boiler is characterized by a design thermal power equal to about $3,500 \mathrm{~kW}$ with a design thermal efficiency ranging between a minimum value equal to $90.4 \%$ and a maximum value equal to $95.4 \%$. Finally, the pumping station of the thermal power plant is composed of three identical pumps, operating in parallel.

\section{DISTRICT HEATING NETWORK ANALYSIS}

The considered DHN has been implemented with IHENA (Intelligent Heat Energy Network Analysis), an inhouse-developed software that allows the simulation of the district heating network behavior and provide a network resolution from both a hydraulic and a thermal viewpoint. Briefly, as it regards the hydraulic resolution of the district heating network, it is based on the Todini-Pilati algorithm generalized on the Darcy-Weisbach equation. On the other 


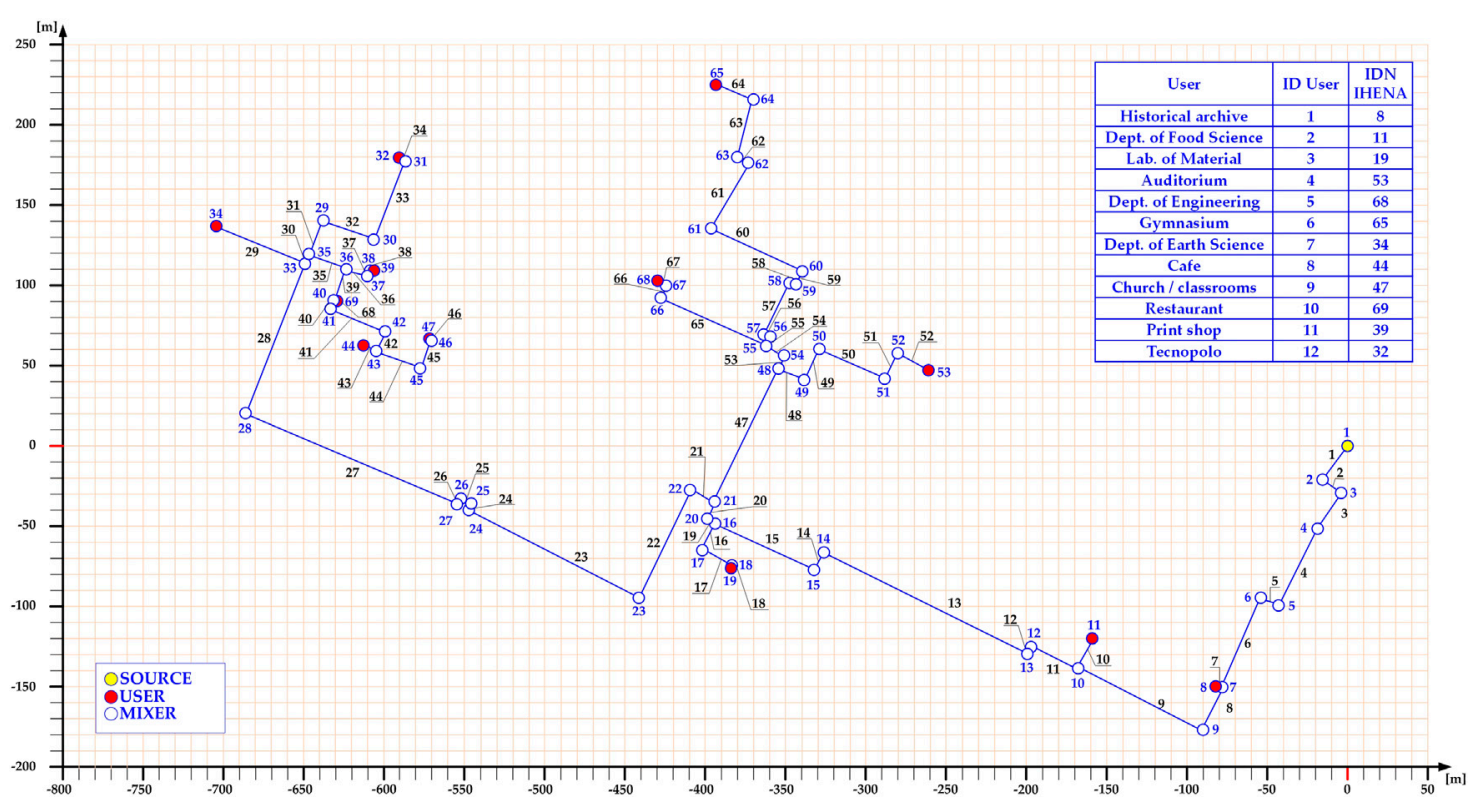

FIGURE 4 | University campus DHN implementation with software IHENA.

TABLE 1 | Design performance results.

\begin{tabular}{lcc} 
Parameter & Units & Value \\
\hline Inlet mass flow rate & {$[\mathrm{kg} / \mathrm{s}]$} & 137 \\
Thermal power supplied to the users & {$[\mathrm{kW}]$} & 11,511 \\
Thermal power from the power station & {$[\mathrm{kW}]$} & 11,657 \\
Heat losses & {$[\mathrm{kW}]$} & 146 \\
Pumping power & {$[\mathrm{kW}]$} & 130 \\
Supply pressure & {$[\mathrm{bar}]$} & 12.32 \\
Expansion vessel pressure & {$[\mathrm{bar}]$} & 4.00
\end{tabular}

hand, the thermal evaluation is carried out by considering the forced convection heat exchange. A more detailed description of the software calculation core can be found in Ancona et al. (2014).

The results of the DHN implementation within the software IHENA is shown in Figure 4 in terms of geometric representation of the network, highlighting also the identification numbers of each node and each pipe. As can be noted from the figure, the model is composed by a total of 69 nodes-a source (i.e., the thermal power station), 12 users and 56 mixers respectively represented in yellow, red, and white-and of 68 pipes. Furthermore, the correspondence between the identification number of the users (ID User) and of the node (IDN) of each user has been also shown in Figure 4.

\section{District Heating Network Design Performance}

As a starting point, the district heating network behavior in design operation has been evaluated. To this respect, the main results of the design evaluation of the network have been listed in
Table 1. In particular, as can be noted from the table, the total thermal power produced by the thermal power station, equal to $11,657 \mathrm{~kW}$, is due to the users' thermal needs (equal to $11,511 \mathrm{~kW})$ plus the heat dissipations along the pipeline of the networks $(146 \mathrm{~kW})$.

Furthermore, it can be observed that the total mass flow rate circulating within the DHN is equal to about $137 \mathrm{~kg} / \mathrm{s}$. This quantity is distributed between the users as shown in Figure 5A. As can be noted from the figure, the minimum value is obtained in line with the user 44 (equal to $0.30 \mathrm{~kg} / \mathrm{s}$ ), while the maximum value is with the user IND68 (equal to about $54 \mathrm{~kg} / \mathrm{s}$ ). This result is in accordance with the thermal needs of each user assumed for the simulation (see Figure 3).

In Figure 5B, instead, the pressure drops of each user resulting from the design analysis are presented. It can be noted that the user IDN68 is characterized by the lower value of pressure drop (equal to 0.50 bar) and therefore it is denoted as the critical users of the network. In this respect, Figure 6 shows the identification of the critical path (i.e., the path from the thermal power station to the critical user) and the flow direction of the water within the supply (feed) line of the whole network.

\section{Prosumers Evaluation}

With the aim of identifying the appropriate user that can be converted into a prosumer and to understand the effect of this conversion on the performances of the whole grid, a series of simulations have been carried out with the software IHENA. In particular, in each simulation one of the twelve users of the network has been set as prosumer (according to the scheme in Figure 1D) and thereby contributing to the thermal energy fulfillment of all the users. In fact, as already said, Scheme 4 allows the introduction of the thermal power into the network without affecting the feed and return temperatures. Obviously, 

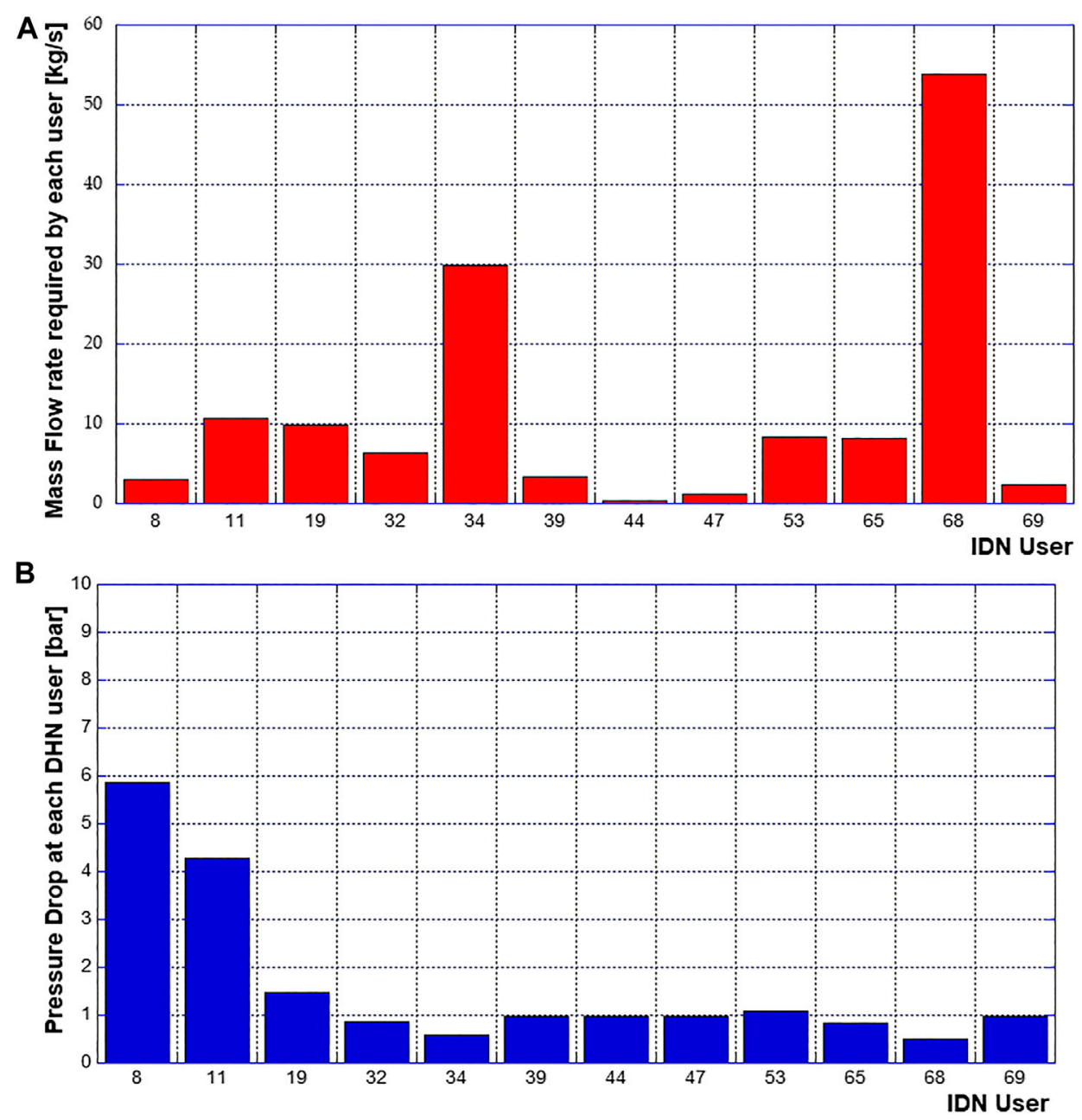

FIGURE 5 | (A) Mass flow rates and (B) pressure drops among the DHN users resulting from the design evaluation.

since it involves a variation in the mass flow rates circulating within the pipelines, it implies some intervention on the user substation. In any case, Scheme 4 is the most appreciated solution on the management point of view.

The main hypotheses of the developed simulations are as follows:

- In each simulation, only one prosumer has been considered. This assumption has been made in order to better understand the thermohydraulic effects of the smart conversion and to define optimal criteria for the choice of the prosumer.

- With the exception of the additional pumping system at each of the considered prosumers substation, no additional pumps and/or valves have been added along the network.

- The feeding pressure has been set at the same value for both the thermal power station and the selected prosumer. The value of this parameter-which has been set in order to keep constant at 0.5 bar the minimum allowed pressure drop across the heat exchanger of the critical user-is a result of the software IHENA.
- The pressure of the expansion vessel has been kept at the design value ( 4 bar).

This means that, according to the resolution performed by the Todini-Pilati algorithm, all the results relating to the optimal hydraulic balance of the network and, therefore, to the mass flow rates and pressures distributions depend only on the network geometry.

A first result, shown in Figure 7A, concerns the change in pumping power consumption with reference to the design case. As can be noted from the figure, the pumping power is reduced in each of the considered cases, showing a minimum value (corresponding to a reduction close to the $85 \%$ with respect of the design case) if the user IDN68 (which is the critical user in the design simulation) is chosen as prosumer.

As expected, the introduction of a prosumer implies a change in the circulating mass flow rate and consequently a change in the direction of the water flow along certain pipes of the network, depending on the selected user to be converted. The change in the circulating mass flow rate (Figure 7B)-evaluated as the ratio between the mass 


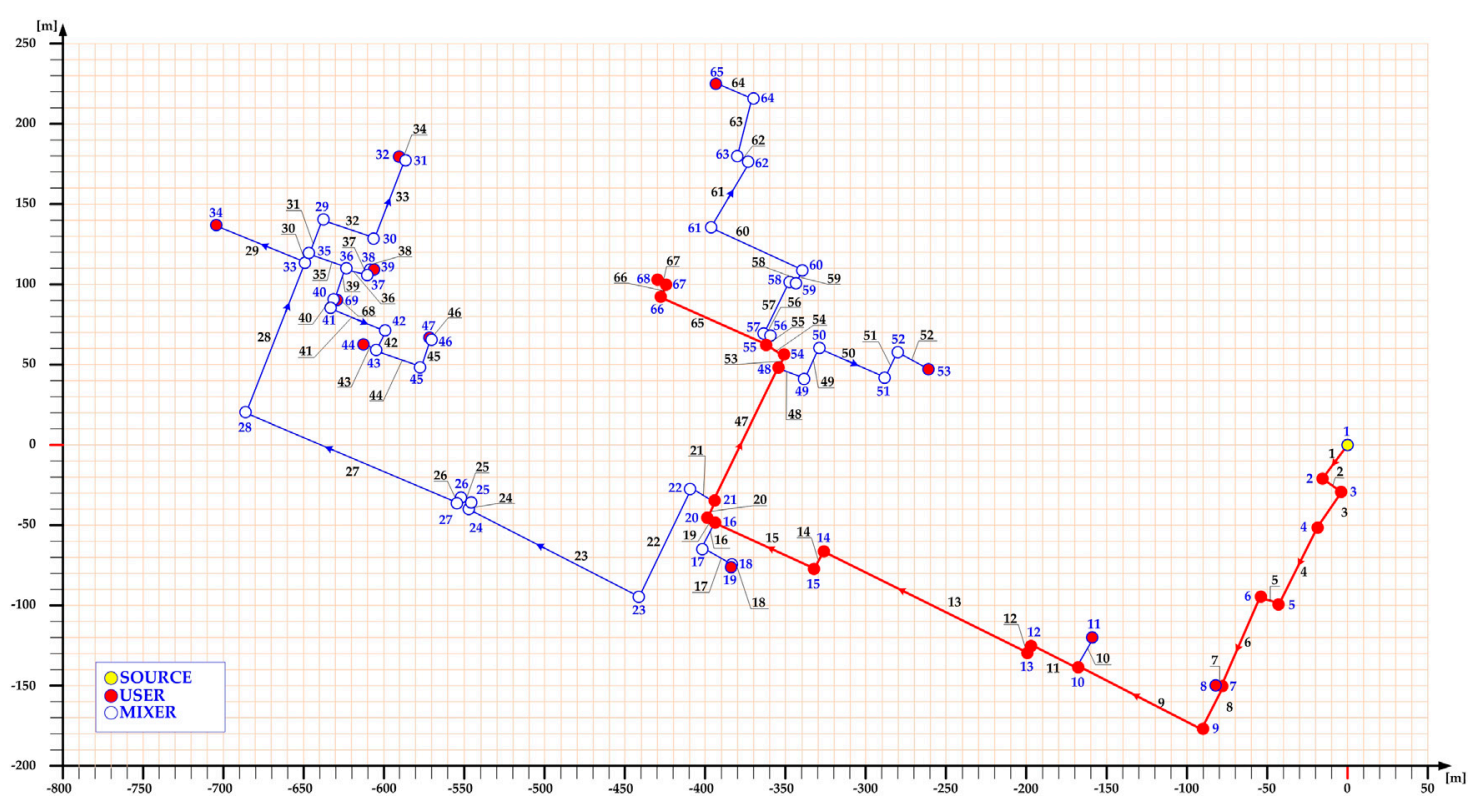

FIGURE 6 | Critical path and flow direction of the water within the supply line of the network.
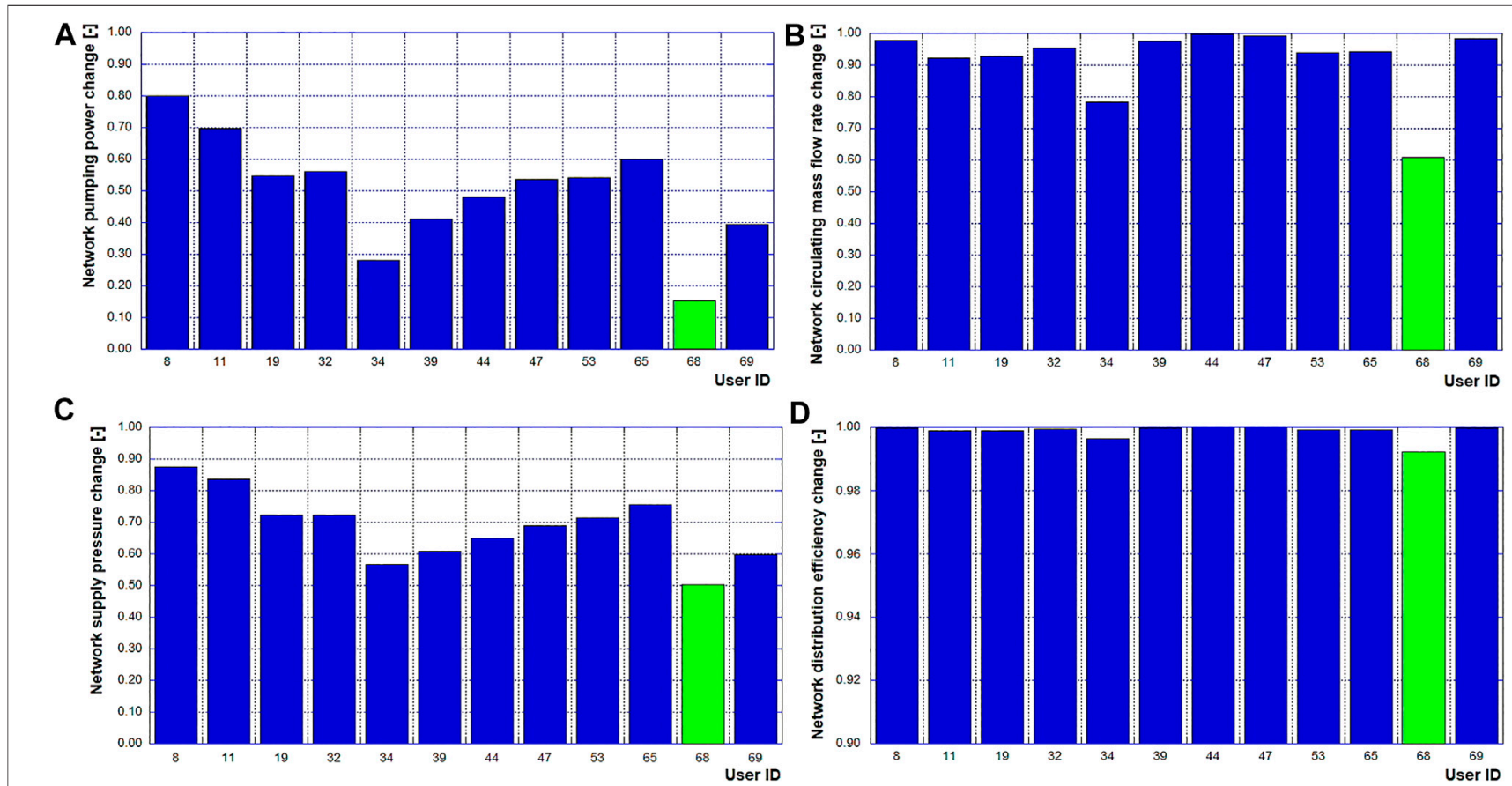

FIGURE 7 | Effect on the network of prosumer allocation: (A) pumping power change, (B)

(B) circulating mass flow rate, (C) supply pressure, and (D) distribution efficiency.

flow rates circulating in each prosumer case and in the design case, respectively-shows a minimum value corresponding to user IDN68 which allows a reduction close to $40 \%$. On the basis of the assumed hypotheses, the supply pressure always reduces with respect to the design value (Figure 7C) and reaches its minimum value-as expected-in case of IDN68 selected as prosumer showing a value slightly higher than 6 bar.

Regarding the distribution efficiency (Figure 7D)—defined as the ratio between the thermal power provided to the users and the 

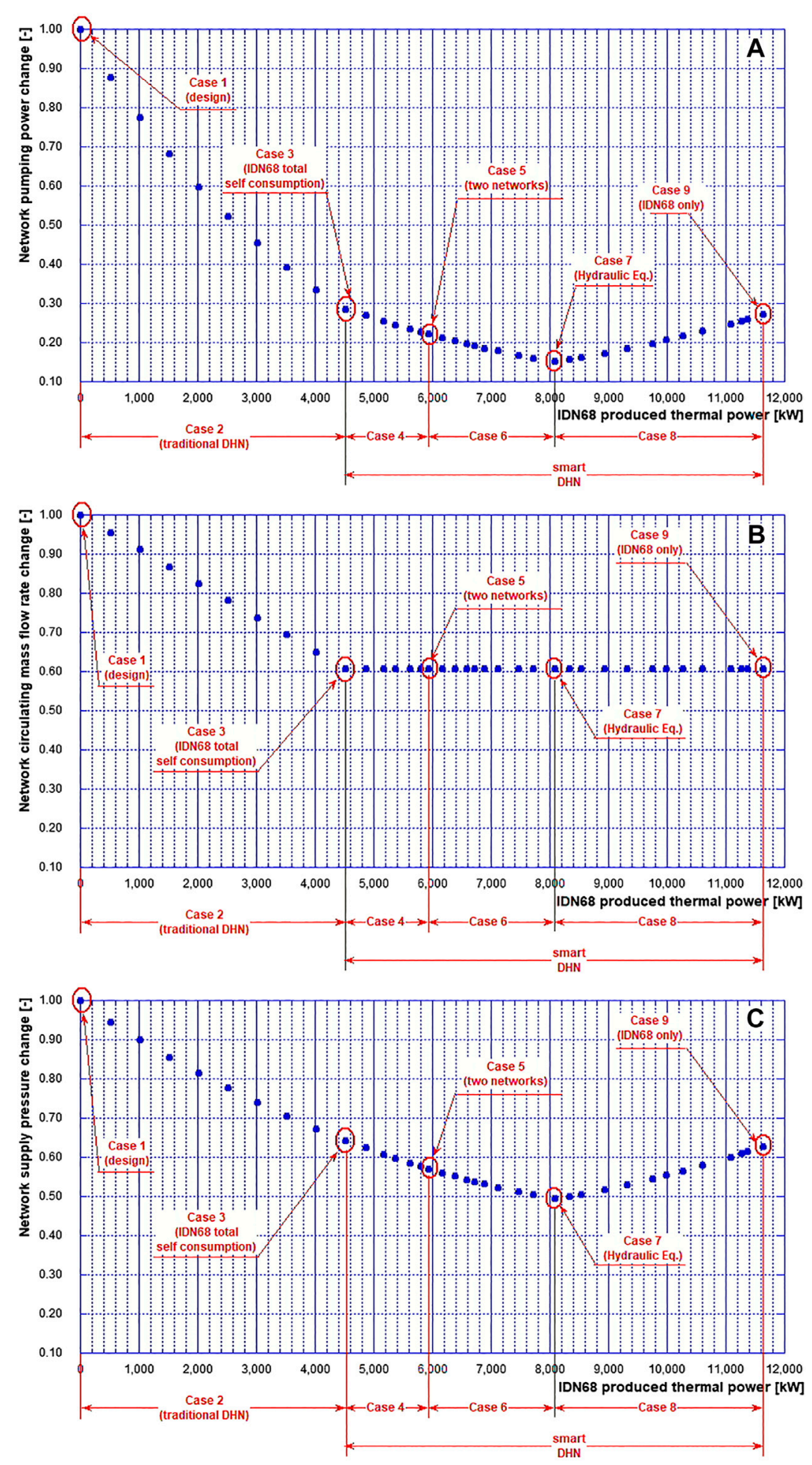

FIGURE 8| Effect of the prosumer-produced thermal power on the network: (A) pumping power, (B) circulating mass flow rate, and (C) supply pressure variation.

thermal power introduced into the network-there is no noticeable change with the introduction of a prosumer. Nevertheless, the figure confirms the opportunity of converting user IDN68.
Based on the results obtained from the simulations, the most suitable user to be converted into a prosumer is the one identified with IDN68. This choice is the most suitable from different points of views, which can be summarized as follows: 


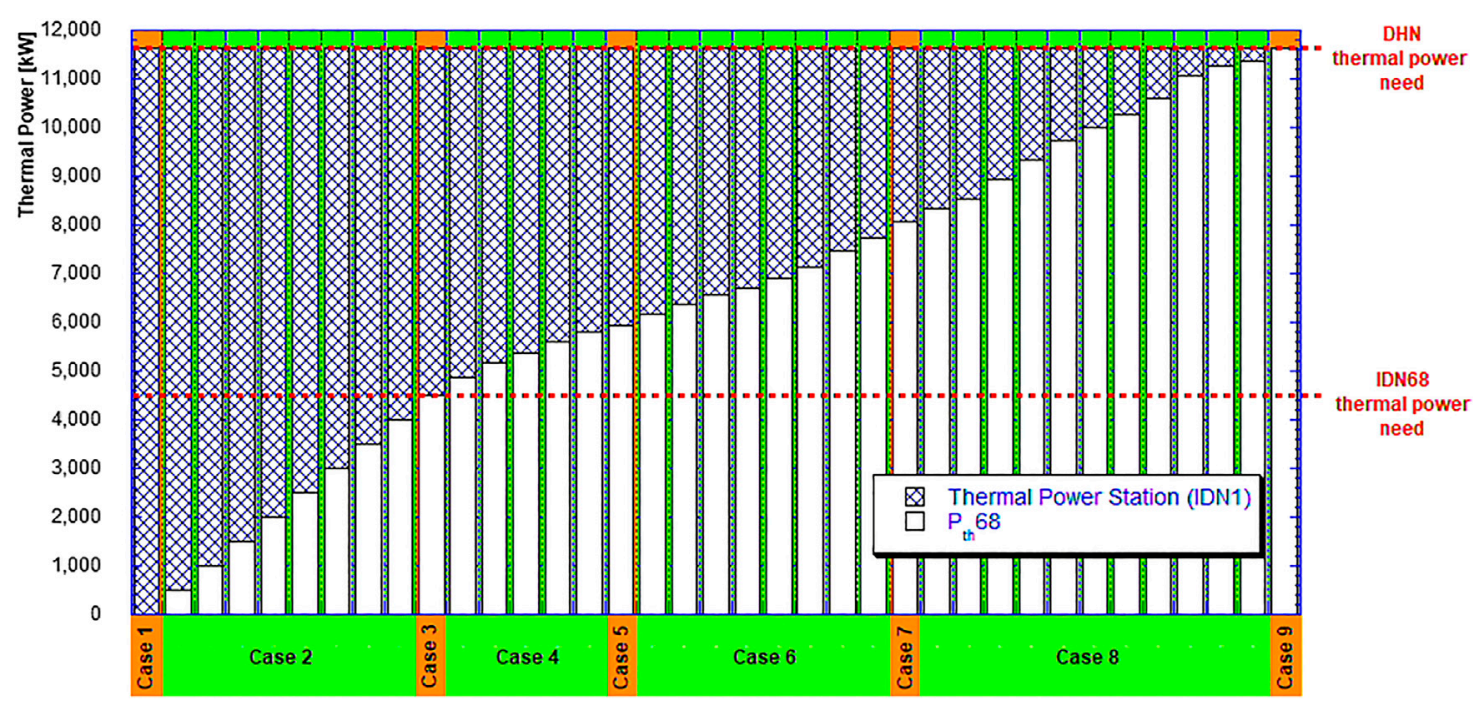

FIGURE 9 | Thermal production, divided between prosumer and thermal power station, for the considered cases.

- From the design performance evaluation (Figure 5A), the user IDN68 results as the critical user, being the one at the end of the path (Figure 6) with the highest pressure losses.

- The conversion of the user IDN68 into a prosumer allows to reach the highest reduction in both the pumping consumption (Figure 7A) and the circulating mass flow rate of water (Figure 7B).

- In case of IDN68 as prosumer, the supply pressure can drop to a minimum value which also implies a reduction in the maintenance costs.

\section{SMART DISTRICT HEATING NETWORK MANAGEMENT}

Once the appropriate user to be converted into prosumer has been identified, the key point is the understanding of the network behavior and its consequent management. These aspects depend on the size of the heat production system installed at the prosumer and on the energy system typology. In this analysis, for the sake of generality, the peculiarities of the user IDN68 (for instance, the surface available on the rooftop for the installation of the solar thermal panels and the free surface in the substation for the installation of a $\mathrm{CHP}$ unit) will be not considered. The aim of this study was to understand the behavior of the network as a function of the amount of thermal power introduced into the network by a prosumer.

On this basis, Figure 8 shows the required pumping power (Figure 8A), circulating mass flow rate (Figure 8B), and supply pressure (Figure $\mathbf{8 C}$ ) changes, as a function of the thermal power produced by the IDN68 distributed generation system. As it will be better explained in the following paragraphs, different scenarios are highlighted in the figure in order to point out a series of network configurations which represent different management and setting approaches.

Furthermore, in Figure 9, the variation in the thermal power produced by the IDN1 (i.e., the thermal power station) with the increase in the production of the distributed generation system at the user IDN68 (this power output will be indicated with $P_{t h} 68$ ) is presented. On the basis of the obtained results, the following scenarios can be defined:

- Case $1 \quad\left(P_{t h} 68=0 \mathrm{~kW}\right)$ : this scenario represents the network behavior in design condition as seen in the results presented in District Heating Network Design Performance (see Figure 6).

- Case $2\left(0 \mathrm{~kW}<P_{t h} 68<4515 \mathrm{~kW}\right)$ : with reference to the users' thermal request in design condition, in this scenario the thermal power produced by the prosumer IDN68 is always lower than its needs. It follows that the behavior of the network is traditional, but the distributed generation system allows the reduction of the thermal power introduced by the unique source (IDN1 in Figure 4). This last evidence means 1) a reduction in the pumping power (Figure $\mathbf{8 A}$ ), 2) a reduction in the water mass flow rate circulating within the network (Figure 8B), and 3) a reduction in the network supply pressure (Figure 8C). In particular, the reduction in water mass flow rate depends on the lower request of IDN68. This implies that, with respect to the design case, a change in the critical user is observed (from IDN68 to IDN34) as well as a change in the water mass flow rate distribution, at least for a part of the network pipes. The IDN34 results the critical user for all the developed simulations from Case 2 to Case 9. The supply pressure of the network has been set by the software IHENA in order to realize a minimum pressure drop at the critical user always equal to $0.5 \mathrm{bar}$.

- Case $3\left(P_{t h} 68=4515 \mathrm{~kW}\right)$ : in this scenario, the distributed generation system is able to completely fulfill the needs of the user IDN68. As a consequence, the user IDN68 can be considered virtually disconnected from the DHN being in total self-consumption. As already seen for Case 2 , a reduction in the circulating mass flow rate and supply pressure occurs while the flow directions along the network remain the same of the design case. In Figure 
A1 of the Supplementary Appendix, the map of the network with the settings required by Case 3 is presented. In particular, in this configuration, the pipes \#65, \#66, and \#67 can be closed at the request of IDN68, from the network point of view being null.

- Case $4\left(4515 \mathrm{~kW}<P_{t h} 68<5931 \mathrm{~kW}\right)$ : this scenario assumes that the distributed generation system is able to produce more than the thermal demand of the user IDN68. This implies that the network becomes smart and the user IDN68 introduces a certain amount of thermal power (and then of mass flow rate of water) into the network. Obviously, as the thermal power introduced into the network from the prosumer increases, the production of the thermal power plant (IDN1) decreases. On this basis, three pipes (\#65, \#66, and \#67) must invert the direction of the flow with respect to the design setting, as shown in Supplementary Appendix Figure A1. The total thermal power introduced into the network remains constant and equal to the value of Case 3, as the user IDN68 is never fulfilled by the network and the thermal needs of the remaining eleven users are constant. As a consequence, the circulating mass flow rate remains constant from Case 3 to the last considered case (Figure 8B). Nevertheless, further reductions of the required supply pressure are observed (Figure 8C).

- Case $5\left(P_{t h} 68=5931 \mathrm{~kW}\right)$ : in this case, the thermal power introduced into the network by the distributed generation system is exactly equal to the sum of the needs of users IDN53 and IDN65. This means that the network can be virtually divided into two separated subnetworks as presented in Supplementary Appendix Figure A2 by closing the pipe \#47. In comparison to Case 4 , also the pipes \#53 and \#54 reverse the flow with respect to the design case. Further reductions in pumping power and supply pressure are observed in this scenario, as presented in Figure 8A and Figure 8C.

- Case $6\left(5931 \mathrm{~kW}<P_{t h} 68<8084 \mathrm{~kW}\right)$ : in this range of thermal power, the number of users fed by the prosumer increases with respect to Case 5. As a consequence, pipe \#47 (see Supplementary Appendix Figure A3) reverses the flow and the node IDN21 becomes a mixer between the production of the thermal power plants (IDN1) and the one of the prosumers.

- Case $7\left(P_{t h} 68=8084 \mathrm{~kW}\right)$ : this case represents the point of the optimal hydraulic balance of the network and its results are the ones already presented in the simulation of Prosumers Evaluation. For this reason, Case 7 shows the lowest values of both required pumping power and supply pressure (Figure 8A and Figure 8C). The setting of the network remains the same as already presented in Supplementary Appendix Figure A3 for Case 6 as it denotes the directions of flow within the network.

- Case $8\left(8084 \mathrm{~kW}<P_{t h} 68<11641 \mathrm{~kW}\right)$ : in this scenario, the continuous increase in the thermal power introduced into the network by the prosumer and the corresponding reduction in the amount supplied by the thermal power plant cause a change in the flow direction along the network in the section from node IDN1 to node IDN21. It must be pointed out that this setting of the network leads to a modification with respect to the optimal hydraulic balance (Case 7) and, consequently, the required pumping power and supply pressure increase. In Figure A4 of the Supplementary Appendix two settings of the network corresponding to two values of $P_{t h} 68$ are presented, in order to underline the evolution of the pipes which reverse their flow depending on the increase in the thermal power introduced by the user IDN68 and on the corresponding decrease in the IDN1 production. As an example, in case of $P_{t h} 68$ equal to about $10273 \mathrm{~kW}$ (namely the smart user fulfills about $89 \%$ of the users need), the reverse flow affects the pipes from the smart user IDN68 to the node IDN16 (in green color in Supplementary Appendix Figure A4) while, in case of $P_{t h} 68$ equal to about 11375 (namely the smart user fulfills about $99 \%$ of the users' needs), the reverse flow affects the pipes from the smart user IDN68 to the node identified with IDN10 (both the green and the orange color pipes).

- Case $9\left(P_{t h} 68=11641 \mathrm{~kW}\right)$ : in this last case, the prosumer produces all the thermal power required by the network users. As a consequence, the setting of the network is the one presented in Supplementary Appendix Figure A5 with a large number of pipes which reverse the flow and some pipes near IDN1 which can be closed. It must be highlighted that the case of smart user as the only thermal source is not a typical configuration that occurs in design conditions. However, according to the aim of the carried-out analysis, it has been considered as one of the possibilities.

The results of the simulations clearly indicate that the behavior of the network, in terms of circulating mass flow rate, flow direction, and pressure distribution, is heavily influenced by the thermal power introduced into the network by the prosumer. Depending on this amount, the reverse flow and/or the opportunity to close a certain portion of the network were observed. It follows that the introduction into the DHN of the thermal power produced by the prosumer cannot be left free, but must be controlled by the network operator. Moreover, the case of distributed generation from renewable nonprogrammable sources at the prosumer, due to their inevitable fluctuations, could empathize the management problems of the network, causing fast setting changes. In this case, an energy storage system at the prosumer is mandatory to gain flexibility in the network operation.

On the other hand, the introduction of prosumers into a district heating network allows the reduction of the expenditure on electricity for the required pumping power and for the thermal power introduced by the centralized power station. This approach is coherent with the penetration of distributed generation, the increase in renewable sources exploitation, and the development of energy districts. It follows that, due to these positive effects, the transformation of one or more users of a traditional district heating network into prosumers should be encouraged, but the concepts at the basis of the network operation and management must be completely revised.

\section{CONCLUDING REMARKS}

This article deals with the optimal allocation of a prosumer in an existing district heating network and on the influence of its produced thermal power on the network behavior. 
To this respect, an existing small/medium district heating network located in the north of Italy has been considered and analyzed by its implementation within the software IHENA.

The results of the prosumers evaluation show that the optimal allocation of a prosumer corresponds to the network critical user. This choice, indeed, allows achieving the maximum reduction in the required pumping power by realizing the optimal hydraulic balance of the network.

Once the optimal prosumer allocation has been identified, nine scenarios, representing different configurations of the district heating network by varying the ratio between the thermal power from the prosumer and the one from the thermal power station, have been simulated and analyzed.

The results confirm the benefits of the conversion of traditional district heating networks into smart networks, but-contemporarily-strongly underline that the thermal power from the prosumer must be managed by the network operator to avoid critical issues due to flow reversions and/or to pressures and mass flow rates distributions.

\section{DATA AVAILABILITY STATEMENT}

The raw data supporting the conclusion of this article will be made available by the authors, without undue reservation.

\section{REFERENCES}

Ancona, M. A., Bianchi, M., Branchini, L., and Melino, F. (2014). District heating network design and analysis. Energy Proc. 45, 1225-1234. doi:10.1016/j.egypro. 2014.01.128

Ancona, M. A., Branchini, L., Di Pietra, B., Melino, F., Puglisi, G., and Zanghirella, F. (2015). Utilities substations in smart district heating networks. Energy. Proc. 81, 597-605. doi:10.1016/j.egypro.2015.12.044

Buffa, S., Cozzini, M., D'Antoni, M., Baratieri, M., and Fedrizzi, R. (2019). 5th generation district heating and cooling systems: a review of existing cases in Europe. Renew. Sustain. Energ. Rev. 104, 504-522. doi:10.1016/j.rser.2018.12.059

Bünning, F., Wetter, M., Fuchs, M., and Müller, D. (2018). Bidirectional low temperature district energy systems with agent-based control: performance comparison and operation optimization. Appl. Energy 209, 502-515. doi:10. 1016/j.apenergy.2017.10.072

European Climate Change Programme. (2020). https://ec.europa.eu/clima/ policies/eccp_en (Accessed October 15, 2020).

Kozarcanin, S., Andresen, G. B., and Staffell, I. (2019). Estimating country-specific space heating threshold temperatures from national gas and electricity consumption data. Energy Build. 199, 368-380. doi:10.1016/j.enbuild.2019.07.013

Lehmann, P., Gawel, E., and Strunz, S. (2019). "EU climate and energy policy beyond 2020: are additional targets and instruments for renewables economically reasonable?," in The European dimension of Germany's energy transition. (Cham, CH: Springer), 11-26.

Lund, H., Möller, B., Mathiesen, B. V., and Dyrelund, A. (2010). The role of district heating in future renewable energy systems. Energy 35 (3), 1381-1390. doi:10. 1016/j.energy.2009.11.023

Lund, H., Werner, S., Wiltshire, R., Svendsen, S., Thorsen, J. E., Hvelplund, F., et al. (2014). 4th Generation District Heating (4GDH): integrating smart thermal grids into future sustainable energy systems. Energy 68, 1-11. doi:10.1016/j. energy.2014.02.089

\section{AUTHOR CONTRIBUTIONS}

MA did the methodology, writing (review and editing), and conceptualization; $\mathrm{MB}$ participated in the supervision; $\mathrm{LB}$ contributed with visualization; AP participated in the supervision; FM conceived the methodology and conceptualization; AP participated in the supervision; JR did simulations and wrote the paper (original draft).

\section{ACKNOWLEDGMENTS}

This research was developed within the context of the Energynius (Energy Networks Integration for Urban Systems) project and funded by the Emilia Romagna Region, under the POR-FESR 2014-2020 financing. The authors gratefully acknowledge the financial support of the EU.

\section{SUPPLEMENTARY MATERIAL}

The Supplementary Material for this article can be found online at: https://www.frontiersin.org/articles/10.3389/fmech.2021.623932/ full\#supplementary-material.

Mathiesen, B. V., Bertelsen, N., Schneider, N. C. A., García, L. S., Paardekooper, S., Thellufsen, J. Z., et al. (2019). Towards a decarbonised heating and cooling sector in Europe. Aalborg: Aalborg Universitet.

Paardekooper, S., Lund, R. S., Mathiesen, B. V., Chang, M., Petersen, U. R., Grundahl, L., et al. (2018). Heat roadmap Europe 4: quantifying the impact of low-carbon heating and cooling roadmaps. Aalborg Universitetsforlag.

Pass, R. Z., Wetter, M., and Piette, M. A. (2018). A thermodynamic analysis of a novel bidirectional district heating and cooling network. Energy 144, 20-30. doi:10.1016/j.energy.2017.11.122

Schmidt, D., Kallert, A., Blesl, M., Svendsen, S., Li, H., Nord, N., et al. (2017). Low temperature district heating for future energy systems. Energy Proc. 116, 26-38. doi:10.1016/j.egypro.2017.05.052

Statistical Office of the European Communities. (1990). EUROSTAT: Regional statistics: reference guide. Luxembourg, LU: Eurostat.

The European Comission. (2015). Fifth generation, low temperature, high exergy district heating and cooling networks. http://cordis.europa.eu/project/rcn/ 194622en.html (Accessed on September 26, 2017).

von Rhein, J., Henze, G. P., Long, N., and Fu, Y. (2019). Development of a topology analysis tool for fifth-generation district heating and cooling networks. Energy Convers. Manage 196, 705-716. doi:10.1016/j.enconman.2019.05.066

Conflict of Interest: The authors declare that the research was conducted in the absence of any commercial or financial relationships that could be construed as a potential conflict of interest.

Copyright (c) 2021 Ancona, Bianchi, Branchini, De Pascale, Melino, Peretto and Rosati. This is an open-access article distributed under the terms of the Creative Commons Attribution License (CC BY). The use, distribution or reproduction in other forums is permitted, provided the original author(s) and the copyright owner(s) are credited and that the original publication in this journal is cited, in accordance with accepted academic practice. No use, distribution or reproduction is permitted which does not comply with these terms. 